\title{
LIBRAS COMO COMPONENTE CURRICULAR OBRIGATÓRIO: UM OLHAR PARA OS CURSOS DE LICENCIATURA EM QUÍMICA DAS TRÊS UNIVERSIDADES ESTADUAIS PAULISTAS
}

\author{
LENGUA BRASILEÑA DE SEÑALES (LIBRAS) COMO COMPONENTE \\ CURRICULAR OBLIGATORIO: UNA MIRADA HACIA LOS CURSOS DE \\ FORMACIÓN DE PROFESORES EN QUÍMICA EN LAS TRES \\ UNIVERSIDADES ESTATALES DE SÃO PAULO
}

\author{
BRAZILIAN SIGN LANGUAGE (LIBRAS) AS A MANDATORY CURRICULAR \\ COMPONENT: A LOOK AT THE CHEMISTRY UNDERGRADUATE COURSES ON \\ THE THREE STATE UNIVERSITIES IN SÃO PAULO
}

\author{
Naira Biagini MALTONI ${ }^{1}$ \\ Júlio Cesar TORRES ${ }^{2}$ \\ Thalita Alves dos SANTOS ${ }^{3}$
}

RESUMO: O Decreto 5.626/2005 estabelece a LIBRAS como componente curricular obrigatório nos cursos de licenciatura e fonoaudiologia. Este trabalho objetiva entender como as três universidades estaduais paulistas ofertam a disciplina nos cursos de licenciatura em Química. Foram analisados oito cursos no total, já que, tirando a Unicamp, tanto a USP quanto a UNESP apresentam essa modalidade em mais de um câmpus. Para coletar os dados, foi feita uma pesquisa online pelos sites das universidades no portal dos referidos cursos, onde foram consultados os horários de aulas e o Projeto Político Pedagógico. Para realizar a discussão dos dados, foi escolhido o método de Bereday, passando pelas etapas de definição, interpretação, justaposição e comparação. À medida que o Decreto não estabelece regras, a pesquisa conseguiu expor como cada universidade elaborou a disciplina e discutir fragilidades e pontos fortes dos métodos escolhidos.

PALAVRAS-CHAVE: Licenciatura em química. LIBRAS. Educação comparada. Políticas públicas.

RESUMEN: El Decreto 5626/2005 establece la Lengua Brasileña de Señales (LIBRAS) como componente curricular obligatorio en los cursos universitarios de formación de profesores y fonoaudiología. Este trabajo tiene como objetivo comprender cómo las tres universidades estatales de São Paulo ofrecen la disciplina en los cursos de formación de profesores en Química. Se analizaron un total de ocho cursos, ya que, excluyendo la Unicamp (Universidad Estatal de Campinas), tanto la USP (Universidad de São Paulo) como

${ }^{1}$ Universidade Estadual Paulista (UNESP), Marília - SP - Brasil. Mestranda pelo Programa de Pós-Graduação em Educação. ORCID: https://orcid.org/0000-0002-0762-1964. E-mail: nairabmaltoni@hotmail.com

${ }^{2}$ Universidade Estadual Paulista (UNESP), São José do Rio Preto - SP - Brasil. Diretor e professor do departamento de Educação. ORCID: https://orcid.org/0000-0002-1002-0078. E-mail: julio.torres@unesp.br

${ }^{3}$ Instituto Federal de São Paulo (IFSP), Presidente Epitácio - SP - Brasil. Técnica em Assuntos Educacionais. Membro do Grupo de Pesquisas Coletivo de Pesquisadores em Políticas Educacionais (COPPE/UNESP). Mestrado em Educação (UNOESTE). ORCID: https://orcid.org/0000-0003-4863-3790. E-mail: thalitaalves@ifsp.edu.br

RPGE- Revista on line de Política e Gestão Educacional, Araraquara, v. 25, n. esp. 4, p. 2004-2017, dez. 2021. e-ISSN: 1519-9029 DOI: https://doi.org/10.22633/rpge.v25iesp.4.15936 
la UNESP (Universidad Estatal Paulista) presentan esta modalidad en más de un campus. Para la recolección de los datos, se realizó una encuesta en línea en los sitios web de las universidades en el portal de los cursos antes mencionados, en que se consultaron los horarios de clases y el Proyecto Político Pedagógico. Para discutir los datos se eligió el método Bereday, pasando por las etapas de definición, interpretación, yuxtaposición y comparación. Como el Decreto no establece reglas, la investigación pudo exponer cómo cada universidad desarrolló la disciplina y discutir las debilidades y fortalezas de los métodos elegidos.

PALABRAS CLAVE: Cursos de formación de profesores en Química. Lengua Brasileña de Señales (LIBRAS). Educación comparada. Políticas públicas.

ABSTRACT: The 5626/2005 Decree establishes Brazilian Sign Language (LIBRAS) as a mandatory curricular component in the Undergraduate Teaching Degree and SpeechLanguage Pathology courses. This work aims to understand how the three state Universities in São Paulo offer these subjects in Chemistry undergraduate courses. A total of eight courses were analyzed, since, except for Unicamp (University of Campinas), both USP (São Paulo University) and UNESP (São Paulo State University) present this modality on more than one campus. To collect the data, an online survey was carried out on the websites of the universities on the portal of the aforementioned courses, in which class schedules and the Pedagogical Political Project were consulted. To discuss the data, the Bereday method was chosen, going through the stages of definition, interpretation, juxtaposition, and comparison. As the Decree does not establish rules, the research was able to expose how each university developed the discipline and discuss weaknesses and strengths of the chosen methods.

KEYWORDS: Chemistry undergraduate courses. Brazilian Sign Language (LIBRAS). Comparative education. Public policies.

\section{Introdução}

O presente artigo busca realizar reflexões sobre o contexto histórico que proporcionou a inserção da Língua Brasileira de Sinais (LIBRAS) como disciplina curricular obrigatória nos cursos de Licenciatura em todo o Brasil e a forma como o Decreto $n^{0}$ 5.626/2005 se materializa nos cursos de Licenciatura em Química de três Universidades públicas paulista.

Para dar início, faremos uma breve revisão histórica da luta das pessoas com deficiência pelos seus direitos, evidenciando suas conquistas e seus desafios, e colocando em foco as pessoas com surdez. Iniciando pelo Renascimento, quando Sêneca, um filósofo do Império Romano, conta que matavam “[...] os fetos e os recém-nascidos monstruosos. [...] Não é devido ao ódio, mas à razão, para distinguirmos as coisas inúteis das saudáveis”. Sobre essa declaração, Olizaroski (2013, p. 6) chama a atenção para uma reflexão, já que esse foi o destino de muitas pessoas com deficiência entre os séculos XIII e XVI, "se os deficientes não tinham sequer direito à vida, jamais chegariam a ter direito à educação." 
Se até o século XVI reconhecer as pessoas com deficiência como portadoras de direitos parecia impossível e improvável, no século XIX a comunidade surda brasileira pôde comemorar uma grande conquista, pelo menos para os homens: em 1857 chegava ao Brasil, a convite de

D. Pedro II, um professor francês, surdo, chamado Hernest Huet, que fundou a primeira escola para surdos aqui no país, atualmente conhecida como INES - Instituto Nacional de Educação para Surdos. Huet era adepto à língua de sinais, o que deu a oportunidade para que surdos brasileiros, finalmente, criassem a LIBRAS. Contudo, no ano de 1880, ocorreu o Congresso Internacional de Surdo-Mudez, em Milão, onde a língua de sinais foi proibida na Europa, sendo permitida, apenas, a comunicação oral. Essa decisão foi acatada pelo Brasil em 1911, mas a LIBRAS sobreviveu nas salas de aula até 1957, quando foi rigorosamente proibida (RAMOS; GOLDFELD, 1992).

No final da década de 1970 surge a Comunicação Total, que era “[...] a prática de usar sinais, leitura orofacial, amplificação e alfabeto digital para fornecer inputs linguísticos para estudantes surdos, ao passo que eles podem expressar-se nas modalidades preferidas" (STEWART, 1993, p. 118). Em 1988, com a Constituição Federal, ficou garantido pelo artigo 208 o "atendimento educacional especializado aos portadores de deficiência, preferencialmente na rede regular de ensino" (BRASIL, 1988). Já em 1994, é adotada a Declaração de Salamanca, que afirma a importância da língua de sinais para as pessoas surdas.

Entrando no século XXI, a Lei $n^{\circ} 10.436 / 2002$ reconhece a LIBRAS como primeira língua (L1) das pessoas com surdez e garante o ensino bilíngue para os surdos. O Decreto $\mathrm{n}^{\mathrm{o}}$ 5.626/2005 regulamenta a Lei $n^{\circ} 10.436 / 02$ e estabelece a inserção da Língua Brasileira de Sinais como disciplina obrigatória na Matriz Curricular dos cursos de Licenciatura e Fonoaudiologia, também garante ao aluno professores bilíngues ou intérpretes na sala de aula, e o reforço escolar em contraturno. Em 2008, entra em vigor o Decreto ${ }^{\circ}$ 186/08 que aprova a Convenção sobre os Direitos da Pessoa com Deficiência. Finalmente, em 2010, a Lei no 12.319 regulamenta a profissão de tradutor e intérprete de LIBRAS. Desde então, notou-se uma união das Universidades do país para contemplar essa nova mudança e, aos poucos, os cursos de Licenciatura e Fonoaudiologia ganharam a LIBRAS como disciplina obrigatória em sua matriz curricular. Além disso, como prevê o decreto, a LIBRAS também se constituiu como disciplina optativa para os outros cursos de ensino superior.

Ao longo de seus capítulos, o Decreto n ${ }^{0} 5.626 / 2005$ não responde ou explica como a disciplina deve ser implementada. Não há menções a carga horária mínima, normas que 
definam seus objetivos, semestre de realização, meios de avaliação e se deve ser realizada de forma presencial ou online. Santos e Campos explicam que "dessa forma, o que pode ocorrer é uma banalização da LIBRAS, de forma que seu ensino apenas cumpra o que é exigido por lei, mas que não contemple as necessidades reais de professores em formação" (2013, p. 240). Pensando nisso, esse trabalho busca evidenciar a forma como três universidades estaduais de São Paulo incluíram essa disciplina nos seus respectivos cursos de Licenciatura em Química. Por meio de um estudo comparativo, seguindo o método da "Abordagem Total" desenvolvido por Bereday (1972), vamos estudar como a LIBRAS, enquanto disciplina obrigatória nos cursos de licenciatura está sendo ofertada nos dias de hoje, para então compreender um pouco mais sobre a atual formação de professores.

\section{Metodologia}

Como forma de desenvolvimento metodológico Bereday (1972) apresenta seu método da "Abordagem Total" composto por quatro momentos: Descrição, Interpretação, Justaposição e Comparação. O primeiro momento é o da descrição, marcado pela descrição detalhada dos dados/fatos pedagógicos coletados. Segue-se do momento da interpretação, que realiza a análise dos dados/fatos por meio dos métodos das diferentes ciências sociais. $\mathrm{O}$ terceiro momento é o da justaposição, neste momento os dados descritos e analisados previamente são submetidos a uma comparação preliminar, suas simitudes e diferenças são destacadas e dão base à formulação de hipóteses. No último momento, o da comparação, compreende o teste das hipóteses com a fusão final dos fatos e com os dados comparativos.

Após a definição do método de análise foram escolhidas para este estudo as três universidades públicas estaduais paulistas: a Universidade Estadual Paulista "Júlio de Mesquita Filho" (UNESP), a Universidade Estadual de Campinas (UNICAMP), e a Universidade de São Paulo (USP). A escolha baseou-se no que elas apresentam em comum: são estaduais; estão localizadas no estado de São Paulo; são universidades com prestígio nacional e internacional; estão entre as cinco melhores universidades do Brasil (QS World University Rankings, 2021). Juntas, elas somam mais de 180mil alunos. Já o interesse pelo curso de Licenciatura em Química, dá-se pela recente graduação desta pesquisadora como Licenciada em Química pela UNESP, em março de 2020.

A coleta de dados foi realizada de forma online, analisando a matriz curricular dos cursos de Licenciatura em Química de sete instituições de ensino superior, sendo quatro campi da UNESP, dois campi da USP e um câmpus da UNICAMP. A pesquisa foi feita no 
site de cada instituição e os focos foram: a) semestre de aplicação; b) carga horária c) formato presencial ou online. De forma simultânea a coleta de dados uma pesquisa documental e bibliográfica foi realizada buscando por amparar a comparação e discussão dos resultados obtidos, apontando críticas, positivas e/ou negativas, a respeito da formação do professor na contemporaneidade. Assim teremos todos os passos e dados que nos permitirão expor um retrato da concretização do Decreto pelas estaduais paulistas. Mas, muito mais do que apenas garantir o que é pedido por lei, poderemos analisar a formação que vem sendo ofertada e compreender se é o suficiente para enfrentar as reais necessidades do professor na sala de aula.

De acordo com Silva (2019, p. 3):

Em se tratando dos Estudos Comparados na educação, alguns pressupostos motivam o processo de comparação: interesses acadêmicos, políticos, econômicos, culturais e sociais, os quais se inter-relacionam e dialogam, auxiliando na construção do processo de educação.

A citação acima reforça nosso objetivo com a produção deste trabalho: obter resultados que nos permitam avaliar o presente, compreender a situação e despertar para as necessidades, podendo, de alguma forma, auxiliar na construção de um processo educacional mais completo, que possibilite não só uma formação de profissionais preparados para encontrar um aluno surdo na aula de aula, mas que também possa garantir a esse aluno um ensino de qualidade e inclusão no ambiente escolar.

\section{Descrição}

\section{Universidade Estadual Paulista "Júlio de Mesquita Filho" - UNESP}

Em 1976, o então governador Paulo Egydio Martins, em acordo com o Secretário da Educação, determinou a criação da Universidade Estadual Paulista "Júlio de Mesquita Filho" a partir da união de Institutos Isolados de Ensino Superior do Estado de São Paulo. Esses Institutos estavam localizados em diferentes pontos do Estado e compreendiam diversas áreas do conhecimento.

Até o final da década de 80, a UNESP tinha 14 campi. Atualmente, são 24 campi espalhados por todo o Estado de São Paulo, localizados nas cidades de: Araçatuba, Araraquara, Assis, Bauru, Botucatu, Dracena, Franca, Guaratinguetá, Ilha Solteira, Itapeva, Jaboticabal, Marília, Ourinhos, Presidente Prudente, Registro, Rio Claro, Rosana, São João da Boa Vista, São José do Rio Preto, São José dos Campos, São Paulo, São Vicente, Sorocaba e 
Tupã. No ano de 2019, a UNESP ofertou 136 cursos de graduação, 263 cursos de pós graduação, e teve um total de 53.578 alunos matriculados entre graduação e pós.

Como nesse estudo buscamos estudar apenas os cursos de Licenciatura em Química, teremos quatro campi da UNESP em evidência: Araraquara, Bauru, Presidente Prudente e São José do Rio Preto.

\section{Araraquara}

O Instituto de Química - Câmpus de Araraquara oferece o curso de Licenciatura em Química no período noturno, com duração mínima de cinco anos, e abre 30 vagas por ano. Conforme a estrutura curricular vigente para alunos ingressantes a partir de 2019, a disciplina de LIBRAS recebe o nome de "Libras, Educação Especial e Inclusiva", realizada no $10^{\circ}$ período da graduação (último semestre), com carga horária de 60 horas e no formato EaD (ensino à distância).

\section{Bauru}

A Faculdade de Ciências - Câmpus de Bauru oferece o curso de Licenciatura em Química também no período noturno, com duração mínima de quatro anos e meio, e disponibiliza 20 vagas por ano. Segundo a estrutura curricular vigente, a disciplina recebe o nome "Libras, Educação Especial e Inclusiva", é obrigatória, realizada no $3^{\text {o }}$ período (primeiro semestre do segundo ano), com carga horária de 30 horas, EaD.

\section{Presidente Prudente}

A Faculdade de Ciências e Tecnologia - Câmpus de Presidente Prudente oferece a Licenciatura em Química no período noturno, com duração mínima de quatro anos e 40 vagas por ano. De acordo com a estrutura curricular vigente, desde 2015, a disciplina intitulada "Libras e Educação Inclusiva" é obrigatória, realizada no $5^{\circ}$ período (primeiro semestre do terceiro ano), com carga horária de 60 horas, também EaD.

\section{São José do Rio Preto}

O Instituto de Biociências, Letras e Ciências Exatas - Câmpus de São José do Rio Preto oferece o curso de Licenciatura em Química em período integral, com duração mínima de quatro anos e 25 vagas por ano. Apesar de a matriz curricular não mostrar a disciplina de LIBRAS, o Projeto Político Pedagógico vigente apresenta toda sua estrutura, intitulada 
"Libras e Educação Inclusiva", a disciplina é obrigatória, deve ser realizada no $7^{0}$ período (primeiro semestre do último ano), com carga horária de 60 horas, EaD.

\section{Universidade de São Paulo - USP}

Fundada em 1934, a USP oferece 183 opções de cursos de graduação, reunindo mais de 58 mil alunos, e 239 programas de pós-graduação, com cerca de 30 mil alunos matriculados. Atualmente, a Universidade de São Paulo é responsável por mais de $20 \%$ da produção científica do país. Os campi estão distribuídos pelas cidades de Bauru, Lorena, Piracicaba, Pirassununga, Ribeirão Preto, Santos, São Carlos e São Paulo.

Os dois campi que oferecem o curso de Licenciatura em Química são o de Ribeirão Preto e o de São Paulo.

\section{Ribeirão Preto}

A Faculdade de Filosofia, Ciências e Letras de Ribeirão Preto oferece a Licenciatura em Química com duração mínima de cinco anos, no período noturno. A grade curricular atual apresenta a disciplina de LIBRAS com o nome "Introdução à Língua Brasileira de Sinais", obrigatória, com carga horária de 30 horas, realizada no $10^{\circ}$ período (segundo semestre do último ano), presencial.

\section{São Paulo}

O Instituto de Química da Universidade de São Paulo oferece o curso de Licenciatura em Química no período noturno, com duração ideal de cinco anos, ou integral, com duração ideal de quatro anos. De acordo com a matriz curricular vigente, tanto o curso noturno quanto o integral têm a disciplina "Educação Especial, Educação de Surdos, Língua Brasileira de Sinais", obrigatória, com carga horária de 60 horas, realizada no $8^{\circ}$ período, presencial.

\section{Universidade Estadual de Campinas - UNICAMP}

Fundada em 1966, a Unicamp oferece 65 opções de cursos de graduação e 158 cursos de pós-graduação, reunindo, juntos, 37.670 alunos matriculados. São quatro cidades que recebem os campi da Universidade Estadual de Campinas: Campinas, Limeira, Piracicaba e Paulínia. O curso de Licenciatura em Química é ofertado pelo câmpus de Campinas (Barão Geraldo). 


\section{Campinas}

O Instituto de Química da Unicamp oferece a Licenciatura em Química no período integral, com duração mínima de quatro anos. A disciplina de LIBRAS é intitulada "LIBRAS e Educação de Surdos", obrigatória, com carga horária de 60 horas, realizada no $7^{\circ}$ período (primeiro semestre do último ano), presencial.

\section{Unindo os dados}

Para uma melhor análise dos dados coletados com a pesquisa online optamos por criar uma figura gráfica de forma a favorecer a análise comparativa entre o período de oferta, a carga horária da disciplina e forma de oferta. A seguir temos o Quadro 01.

Quadro 1 - Dados da disciplina de libras dos cursos de licenciatura em química das três universidades públicas estaduais paulistas

\begin{tabular}{|l|c|c|c|}
\hline Universidade & Período & Carga Horária & Presencial \\
\hline UNESP & $10^{\circ}$ & 60 horas & Não \\
\hline $\begin{array}{l}\text { Araraquara } \\
\text { (noturno) }\end{array}$ & $3^{\circ}$ & 30 horas & Não \\
\hline Bauru (noturno) & $5^{\circ}$ & 60 horas & Não \\
\hline $\begin{array}{l}\text { P. Prudente } \\
\text { (noturno) }\end{array}$ & $7^{\circ}$ & Não \\
\hline S. J. do Rio Preto & $10^{\circ}$ & 60 horas & Sim \\
\hline USP & $8^{\circ}$ & 60 horas & Sim \\
\hline Ribeirão Preto & $8^{\circ}$ & 60 horas & Sim \\
\hline São Paulo (integral) & & & Sim \\
\hline São Paulo (noturno) & $7^{\circ}$ & 60 horas & \\
\hline UNICAMP & & & \\
\hline Campinas & & & \\
\hline
\end{tabular}

Fonte: Elaborado pelos autores

Com a análise do quadro acima é possível inferir que cinco, dos oito cursos, ofertam a disciplina de LIBRAS no último ano da graduação; que apenas a UNESP Bauru e a USP 
Ribeirão Preto ofertam a disciplina com a carga horária inferior a 60 horas; que os quatro campi da UNESP ofertam a disciplina na modalidade de EaD, enquanto USP e Unicamp trabalham com o formato presencial.

\section{Comparação}

Iniciaremos essa análise comparando o tópico "período" do Quadro 1. A maioria dos cursos opta por oferecer a LIBRAS nos dois últimos anos da graduação, mas dois campi da UNESP colocam a disciplina nos anos iniciais, que é o caso de Araraquara e Bauru. Não há nada nos documentos oficiais que faça menção ao semestre de oferta da disciplina, então podemos dizer que não existe certo ou errado. Os projetos políticos pedagógicos dos cursos da UNESP esclarecem que a Reitoria é a responsável por pensar e realizar a disciplina de LIBRAS, sendo assim, o material oferecido $\mathrm{EaD}$ é o mesmo para todos os campi da Universidade Estadual Paulista, tendo tutores que auxiliam nas reflexões e discussões, e avaliam as atividades dos alunos. Acreditamos que, por esse motivo, os campi da UNESP apresentam semestres intercalados na realização da disciplina, já que a equipe de tutores precisa auxiliar muitos alunos e aqui estamos falando apenas da Licenciatura em Química. Já na USP e Unicamp, os responsáveis pela LIBRAS podem ser diferentes faculdades, como da Educação ou Fonoaudiologia.

Colocando o foco na coluna "Carga Horária”, UNESP Bauru e USP Ribeirão Preto são os únicos campi que oferecem a disciplina com carga horária de 30 horas. Como dito anteriormente, o Decreto também não estipula nem sugere uma carga horária. Pessoalmente, acreditamos que a carga horária mínima para essa disciplina deveria ser 60 horas, como nas outras seis instituições aqui mencionadas. $\mathrm{Na}$ descrição da disciplina, as três universidades apresentam como tópicos a serem estudados: história da comunidade surda, história da LIBRAS, leis e políticas, e a própria LIBRAS. De forma resumida, apresentamos aqui pelo menos quatro tópicos complexos e profundos, e que dificilmente conseguem ser trabalhados em 30 horas. Além de que, muito mais do que aprender os sinais, é necessário praticar a Língua de Sinais.

O último, mas não menos importante item do Quadro 1: a categoria "presencial”. USP e UNICAMP ofertam a disciplina na modalidade presencial. Já os quatro campi da UNESP ofertam EaD. Entendemos que, como forma de padronizar e garantir a disciplina para todos os campi, a medida da UNESP foi tornar EaD e unificar o material. Já as outras Universidades, que têm faculdades de Educação e/ou Fonoaudiologia em suas sedes, conseguem ofertar a 
LIBRAS de forma presencial. Cabe aqui dizer que não queremos deslegitimar o ensino a distância, mas acreditamos que o ensino presencial propicia muito mais experiências, troca, dinamismo, práticas, conversas, curiosidades, interações e assim segue uma lista das infinitas possibilidades da sala de aula. Tais apontamento já tem sido investigado, um dos trabalhos encontrado é de Santos et al. (2015, p. 219) que em seus estudos evidenciaram que "o ensino ministrado desta forma tende a ser simplificado, com enfoque em conteúdos teóricos e que valorizam um ensino mais individualizado e autônomo do aluno".

De forma geral, as três Universidades apresentam um plano de ensino muito parecido para a LIBRAS, independentemente de sua carga horária e de seu semestre e forma de aplicação. Os métodos de avaliação também não se diferem muito, nem os próprios nomes das disciplinas. Os objetivos que estão descritos no PPP de cada curso são muito similares. O que nos cabe agora, diante destes resultados, é tentar compreender se a forma como a disciplina está sendo pensada e ofertada pelas Universidades tem tido resultado para os formados que atuam no mercado de trabalho.

Sabemos também que a disciplina se tornou um componente curricular obrigatório para que os alunos conheçam o tema e possam conhecer outras realidades, que consigam abrir portas para a criatividade e que aprendam um pouco mais sobre diversidade e inclusão. Não estamos aqui culpando a Universidade por não formar o discente bilíngue, porque a escola deve oferecer um tradutor intérprete de LIBRAS para o aluno surdo, mas nos preocupamos com a interação aluno surdo-professor e com a consciência desse professor sobre a luta da comunidade que seu aluno faz parte.

\section{Conclusão}

Foi objetivo deste artigo comparar as disciplinas de LIBRAS das três universidades públicas estaduais do estado de São Paulo, evidenciando a forma como são ofertadas: semestre de realização, carga horária e modalidade presencial ou online. Os resultados foram compilados e exibidos no Quadro 1, onde pudemos analisar cada tópico e concluir que, embora a disciplina não se apresente do mesmo modo entre as Universidades, elas são bastante parecidas em seus objetivos e ideias.

Mesmo que o Decreto não mencione detalhes da disciplina, UNESP, USP e UNICAMP parecem ter o mesmo propósito em mente e, apesar de termos ressalvas quanto a algumas particularidades, compreendemos que as três estão buscando o mesmo caminho para seus alunos. Então o que poderia ser complementar para o currículo desses discentes? 
Inúmeros autores relatam e defendem a importância de um estágio supervisionado. Oliveira e Mourão (2012) trazem o relato do estágio supervisionado especificamente realizado com alunos surdos, e demonstram o quão importante foi para o acadêmico ter esse contato, o quanto reforçou o aprendizado da LIBRAS, proporcionou novos vocabulários, aumentou o interesse pela Língua e possibilitou o contato com os métodos e adaptações de aula.

Disciplina alguma tem o poder de preparar um discente cem por cento para a vida fora dos muros da universidade, mas elas guiam, e o estágio seria fundamental para que os profissionais em formação tivessem contato com a realidade e assim fossem melhor preparados para a sala de aula e para o dia-a-dia com o aluno surdo.

Para finalizar, o Decreto $n^{0} 5.625 / 2005$ foi uma conquista extremamente preciosa para a comunidade surda, ter a LIBRAS como componente curricular obrigatório não só é transformador como revolucionário. A forma como ela é ofertada hoje pode ainda não ser a ideal, mas podemos chegar lá. Ao término das pesquisas apenas fica o questionamento: o aluno surdo é o único aluno que o professor pode encontrar na escola? Quantas disciplinas os licenciandos deveriam realmente cursar para assim estarem preparados para as surpresas da sala de aula? A resposta: nós não sabemos. Mas ser professor é ensinar e aprender, o importante é nunca parar de estudar, de se adaptar, é nunca parar de lutar.

\section{REFERÊNCIAS}

ANUÁRIO estatístico. Universidade Estadual de Campinas, 2020. Disponível em: https://www.aeplan.unicamp.br/anuario/2020/filipeta2020_port.pdf. Acesso em 10 de junho de 2021

BEREDAY, G. Z. F. Método comparado em educação. São Paulo: Ed. Nacional, 1972.

BRASIL. Constituição (1988). Constituição da República Federativa do Brasil. Brasília, DF: Centro Gráfico, 1988. Disponível em:

http://www.planalto.gov.br/ccivil_03/constituicao/constituicao.htm. Acesso em: 10 jun. 2021.

BRASIL. Ministério da Educação. Secretaria de Educação Especial. Lei Federal n. 9.394, de 20 de dezembro de 1996. Estabelece as diretrizes e bases da educação nacional. Brasília, DF: MEC, SEESP, 1996. Disponível em:

http://portal.mec.gov.br/seed/arquivos/pdf/tvescola/leis/lein9394.pdf. Acesso em: 10 jun. 2021.

BRASIL. Lei n. 10.436, de 24 de abril de 2002. Dispõe sobre a Língua Brasileira de Sinais Libras e dá outras providências. Brasília, DF, 2002. Disponível em:

http://www.planalto.gov.pr/ccivil03/ato2004- 2006/decreto/d5.626.htm. Acesso em: 10 jun. 2021. 
BRASIL. Decreto n. 5.626, de 22 de dezembro de 2005. Regulamenta a Lei $n^{\circ} 10.436$, de 24 de abril de 2002, que dispõe sobre a Língua Brasileira de Sinais -Libras e dá outras providências. Brasília, DF, 2005. Disponível em:

http://www.planalto.gov.pr/ccivil03/ato2004-2006/decreto/d5.626.htm. Acesso em: 10 jun. 2021.

BRASIL. Lei n. 12.319, de 1 de setembro de 2010. Regulamenta a profissão de Tradutor e Intérprete da Língua Brasileira de Sinais - LIBRAS. Brasília, DF, 2010. Disponível em: http://www.jusbrasil.com.br/legislação. Acesso em: 10 jun. 2021.

CAETANO, J. F.; LACERDA, C. B. F. LIBRAS no currículo de cursos de licenciatura. In: LACERDA, C. B. F. Tenho um aluno surdo, e agora? 1. ed. São Carlos, SP: Editora da Universidade Federal de São Carlos, 2013. cap. 13.

CARRARO, E. A.; DEL MOURO, K. A. G. O processo histórico da Língua Brasileira de Sinais. In: ENCONTRO CIENTÍFICO E TECNOLÓGICO - ENCITEC, 12., 2016, Cascavel. Anais [...]. Cascavel, PR: FAG TOLEDO, 2016. p. 10-13.

DUARTE, S. A. B. Releitura histórica da educação de surdos no Brasil: 1961 - 1996. 2009. Dissertação (Mestrado em Educação) - Universidade Federal de Uberlândia, Uberlândia, 2009.

ESTATÍSTICA de inscritos. Universidade Estadual Paulista, 2021. Disponível em: https://documento.vunesp.com.br/documento/stream/MjAwMTE3NA\%3d\%3d. Acesso em: 10 jun. 2021.

ESTRUTURA curricular. Universidade Estadual Paulista, 2021. Disponível em: https://www.iq.unesp.br/Home/graduacao/licenciaturaemquimica/estrutura-curricular-lic2019-para-site.pdf. Acesso em: 10 jun. 2021.

FACHIN, O. Fundamentos de metodologia. 5. ed. São Paulo: Saraiva, 2006.

GRADE curricular. Universidade de São Paulo, 2020. Disponível em: https://docs.google.com/spreadsheets/d/e/2PACX-1vQvJLrA86M8EehGWgnZk_TzhKzJ_M0RqSk6Voy0JpyOclMnaKwIwyl7f2EjSRVvq0QEaZwe58YJdZI/pubhtml. Ācesso em: 10 jun. 2021.

GRADE curricular. Universidade de São Paulo, 2021. Disponível em: https://docs.google.com/spreadsheets/d/e/2PACX1vQ0RyxNC4Nj6jqiWDLGHKrddpxfYSw2uMY3VsuAD7jLUu3V2UEcxxv0Az3cm37Kzof uew6X0sirPwXi/pubhtml. Acesso em: 10 jun. 2021.

GRADE curricular. Universidade de São Paulo, 2021. Disponível em: https://uspdigital.usp.br/jupiterweb/listarGradeCurricular?codcg $=46 \& \operatorname{codcur}=46300 \& \operatorname{codhab}$ $=200 \&$ tipo $=$ N. Acesso em: 10 jun. 2021 .

GRADE curricular. Universidade de São Paulo, 2021. Disponível em: https://uspdigital.usp.br/jupiterweb/listarGradeCurricular?codcg $=46 \&$ codcur $=46300 \&$ codhab $=204 \&$ tipo $=$ N. Acesso em: 10 jun. 2021 . 
GRADE curricular. Universidade Estadual Paulista, 2021. Disponível em:

https://www.ibilce.unesp.br/Home/Graduacao450/quimica/quilq2019.pdf. Acesso em: 10 de junho de 2021.

GRADE curricular. Universidade Estadual Paulista, 2021. Disponível em:

https://www.fc.unesp.br/Home/Departamentos/quimica201/gradescurriculares/licenciaturaem-quimica.pdf. Acesso em: 10 de junho de 2021.

GRADE curricular. Universidade Estadual Paulista, 2021. Disponível em:

https://www.fct.unesp.br/Home/Graduacao/Quimica/grade-nova-curso-de-licenciatura---apartir-de-2015.pdf. Acesso em: 10 jun. 2021.

GRADE curricular. Universidade Estadual Paulista, 2021. Disponível em:

https://www.ibilce.unesp.br/Home/Graduacao450/quimica/quinb2019.pdf. Acesso em: 10 jun. 2021.

HISTÓRIA da UNICAMP. Universidade Estadual de Campinas, 2016. Disponível em: https://www.unicamp.br/unicamp/historia. Acesso em: 10 jun. 2021.

HISTÓRIA da USP. Universidade de São Paulo, 2021. Disponível em: https://www5.usp.br/institucional/a-usp/. Acesso em: 10 jun. 2021.

OLIVEIRA, P. S. J.; MOURÃO, M. P. Estágio Supervisionado e a Educação de Surdos: a importância do bilinguismo. Anais do SIELP, Uberlândia, v. 2, n. 1, p. 1-9, 2012.

OLIZAROSKI, I. M. H. Trajetória histórica do sujeito surdo e reflexões sobre as políticas públicas que regem a educação dos surdos no Brasil. In: JORNADA DO HISTEDBR - A PEDAGOGIA HISTÓRICO-CRITICA, A EDUCAÇÃO BRASILEIRA E OS DESAFIOS DA SUA INSTITUCIONALIZAÇÃO, 11., 2013, Cascavel. Anais [...]. Cascavel, PR, 2013.

PROJETO de reestruturação do curso. Universidade Estadual Paulista, 2021. Disponível em: https://www.fc.unesp.br/Home/Departamentos/quimica201/gradescurriculares/ppp-2904.pdf. Acesso em: 10 jun. 2021.

PROJETO político pedagógico. Universidade de São Paulo, 2021. Disponível em: https://edisciplinas.usp.br/pluginfile.php/3129257/mod_resource/content/1/PPP_Licenciatura _Qu\%C3\%ADmica.pdf. Acesso em: 10 jun. 2021.

RAMOS, C. R.; GOLDFELD, M. Vendo vozes: os passos dados na direção da realização de um programa de televisão para crianças surdas. Revista Geles, Rio de Janeiro, n. 6, ano 5, 1992.

SANTOS, L. F. et al. Desafios tecnológicos para o ensino de libras na educação a distância. Comunicações, Piracicaba, ano 22, n. 3, p. 203-219, 2015.

SANTOS, L. F.; CAMPOS, M. L. I. L. O ensino de LIBRAS para futuros professores da educação básica. In: LACERDA, C. B. Tenho um aluno surdo, e agora? 1. ed. São Carlos, SP: Editora da Universidade Federal de São Carlos, 2013. cap. 14. 
SILVA, K. R. L. Educação Comparada - o conceito que desafia. Revista Brasileira de Educação Comparada, Campinas, v. 1, p. 1-11, 2019.

SOUZA, R. A. A Implantação da Libras nas Licenciaturas: desmistificando conceitos. Revista Educação, Artes e Inclusão, v. 13, n. 3, p. 74-97, 2017.

STEWART, D. A. Pesquisa sobre o uso de sinais na educação de crianças surdas. In: Moura, M. C.; LODI, A. C. B.; PEREIRA, M.C.C. (org.). Língua de sinais e educação do surdo. São Paulo: Tec Art, 1993.

\section{Como referenciar este artigo}

MALTONI, N. B.; TORRES, J. C.; DOS SANTOS, T. A. LIBRAS como componente curricular obrigatório: um olhar para os cursos de licenciatura em química das três universidades estaduais paulistas. Revista on line de Política e Gestão Educacional, Araraquara, v. 25, n. esp. 4, p. 2004-2017, dez. 2021. e-ISSN:1519-9029. DOI: https://doi.org/10.22633/rpge.v25iesp.4.15936

Submetido em: 20/08/2021

Revisões requeridas em: 12/10/2021

Aprovado em: 15/11/2021

Publicado em: 08/12/2021 